meter was passed. Centred on this screw and resting on the cast iron plate was a bevel wheel, which received motion from a pinion in connexion with spur-gearing worked by crank handles in the ordinary manner. On the lower end of the large screw was forged an eye, to receive a cross-bar, having links at each extremity, which hooked under the angle irons at the sides of the girlers. With six men at the handles, each girder was raised and lowered into its place in one hour. When one line of girders was thus completed-the whole of the traffic having in the meanwhile been carried by a single road-a temporary way was laid upon this line of girders, and the traffic was transferred to it. The girders on the other side of the viaduct were next constructed, and when they were finished the iron cross-beams were riveted to these girders, and the permanent way for this line was made good. The trains were again passed on to this road, the permanent way on the other side was laid, the timber arches and the framing were removed, and the viaduct was complete.

\title{
Experiments on the Gauging of Water by Triangular Notches.
}

By James Thomas, M. A., Prof. C. E. Queen's Col. Bel.

From the Lnad. Civ. Fing. and Arch. Journal, April, 1883.

With reference to the comparison male, in the conclading sentences of the Report, between the quantities of water which for any given depth of flow are discharged by notches of different widths, and to the opinion there expressed that we might, without danger of falling into important error, pass from the experimental determination of the coefficient for a notch so wide as four times its depth, to the employment of notches wider in any degree, by simply increasing the coefficient in the same ratio as the width of the noteh for a given depth is increased, I now wish to add an investigation, since made, which confirms that opinion, and extends the determination of the discharge beyond the notches experimented on, to notches of any widths great in preportion to their depths. This investigation is founded on the formula for the flow of water in rectangular notches obtained from elaborate and careful experiments made on a very large scale by $\mathrm{Mr}$. James B. Francis, in his capacity as engineer to the Water-power Corporation at Lowell, Massachusetts, and described in a work by him, entitled "Lowell Mylranlic Experiments," Boston, 1855. That formula, for either the case in which there are no end-contractions of the vein, or for that in which the length of the weir is great in proportion to the depth of the water aver its erest, and the flow over a portion of its length not extending to eithor ond is alone considered, is

$$
\mathrm{Q}_{1}=3.33 \mathrm{I}_{\mathrm{A}_{1}} \mathrm{H}_{\mathrm{L}}^{3} \stackrel{3}{2} \text {. . (1) }
$$

where $L_{1}=$ length of the weir over which the water flows, without endcontractions; or length of any part of the weir not extending to the ends, in feet;

$\mathrm{H}_{1}=$ height of the surface-level of the impounded water, measured vertically from the crest of the weir, in feet;

and $Q_{1}=$ discharge in cubic feet per second over the length $L_{1}$ of the weir. 
It is to be understood that, in cases to which this formula is applicable; the weir has a vertical face on the upstream side, terminating at top in a level crest; and the water on leaving the crest is discharged through the air, as if the weir were a vertical thin plate.

To apply this to the case of a very wide triangular notch. Let A BC be the crest of the notch, and $A C$ the water level in the impounded pool. Let the slopes of the crest be each $m$ horizontal to 1 vertical ;

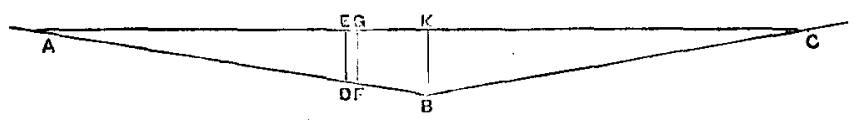

or, what is the same, let the cotangent of the inclination of each side of the crest to the horizon $\mathrm{be}=m$. Let $\mathrm{A} \mathrm{E}$, a variable length, $=x$. Then E $\mathrm{D}=\frac{x}{m}$. Let $\mathbf{E} \mathrm{G}$ be an infinitely small element of the horizontal length or width from $\mathrm{A}$ to $\mathrm{C}$. Then $\mathrm{E} G$ may be denoted by $d x$. Let $q=$ quantity in cubic fect per second flowing under the length $x$, that is, under $\mathrm{AE}$ in the figure. Then $d q$ will be the quantity discharged per second between $E \mathbf{D}$ and $\mathrm{G} F$. Then, by the Lowell formula just cited, we have

$$
d q=3 \cdot 33 d x\left(\frac{x}{x \imath}\right)^{3}
$$

whence, by integrating, we get

$$
q=3 \cdot 33 \frac{1}{m_{: 2}^{3}} \cdot \tilde{5} x^{\frac{5}{2}}+\mathrm{c},
$$

in which the constant quantity is to be put $=0$, because when $x=0$, $q$ also $=0$. Hence we have

$$
q=\frac{2}{5} \times 3 \cdot 33 \frac{1}{m_{2}^{3}} x_{2}^{5} . \quad . \quad .
$$

Let now $\mathrm{H}_{2}=$ height in feet from the vertex of the noteh up to the level surface of the impounded water $=B K$ in the figure. Then $A K$ $=m \mathrm{H}_{2}$. Let also $\mathrm{Q}_{2}=$ the lischarge per second in the whole triangular notch $=$ twice the quantity discharged under $\mathrm{A} \mathrm{K}$. Then, by formula (2), we get

$$
\begin{gathered}
Q_{2}=\frac{4}{5} \times 3.38 \times \frac{1}{m 3}\left(m \mathrm{H}_{2}\right)_{2}^{5} ; \text { or } \\
\Omega_{2}=2.664 \mathrm{~m} \mathrm{H}_{2}^{5} .
\end{gathered}
$$

To bring the notation to correspond with that used in the foregoing report, let $q=$ the quantity of water in cubic feet per minute, and $\mathrm{II}=$ the height of the water level above the vertex in inches. Then

$$
\mathrm{Q}_{2}=\underset{60}{\mathrm{Q}} \text {, and } \mathrm{H}_{2}=\frac{\mathrm{I}}{12} \text {; }
$$

and, by substitution in (3), we get

$$
\mathrm{Q}=.320 \mathrm{mH}_{\mathbf{2}}^{5}
$$

This formula then gives, deduced from the Lowell formula, the flow 
in cubic feet per minute through a very wide notch in a vertical thin plate, when $H$ is the height from the vertex of the notch up to the water level in inches, and when the slopes of the notch are each $m$ horizontal to 1 vertical.

As to the confidence which may be placed in this formula, I think it clear that, for the case in which the notch is so wide, or what is the same, the slopes of its edges are so slight that the water may flow over each infinitely small element of the length of its crest without being sensibly influenced in quantity by lateral contraction arising from the inclination of the edges, the formula may be relied on as having all the accuracy of the Lowell formula from which it has been derived; and I would suppose that when the notch is of such width as to have slopes of about four or five to one, or when it is of any greater width whatever, the deviation from accuracy in consequence of lateral contraction might safely be neglected as veing practically unimportant or inappreciable.

This formula for wide notches bears very satisfactorily a comparison with the formulas obtained experimentally for narrower notches, as described in the foregoing report. For slopes of one to one the formula $Q=\cdot 305 \mathbf{H}_{2}^{5}$, and for slopes of two to one the formula was $\mathrm{Q}=\cdot 636 \mathrm{H}_{3}^{5}$. To compare these with the one now deduced for any very slight slopes, we may express them thus:-

For slopes of 1 to 1

And for slopes of 2 to

$$
\begin{aligned}
& \mathrm{Q}=\cdot 305 \mathrm{~m} \mathrm{H}_{\dot{z}}^{5} \\
& \mathrm{Q}=\cdot 318 \mathrm{H}_{\mathfrak{z}}^{5}
\end{aligned}
$$

While for any very slight slopes, or for any very wide notches, the formula now deduced from the Lowell one is . . $Q=.320 \mathrm{~m} \mathrm{H}_{3}^{5}$

The very slight increase from $\cdot 318$ to .320 here shown in passing from the experimental formula for notches with slopes of two to one, to notches wider in any degree-that slight change, too, being in the right direction, as is indicated by the increase from $\cdot 305$ to $\cdot 318$ in passing from slopes of one to one to slopes of two to one-gives a verification of the concluding remarks in the foregoing report; and this may serve to induce confidence in the application in practice of the formula now offered for wide notches.

Structures in the Sea, without Coffer Dams: with a Description of Works of the New Albert Harbors at Greenock. By D. Milden. From the London Artizan, May, 1513.

It was stated that the imrrediate object of this paper was to treat of the various methods of constructing the foundations of quays, walls, piers, or breakwaters, for the formation of docks and harbors in deep water; and to describe works of this kind which have been carried out on principles different to those usually practised, and to point out the further application of those principles to other structures of a similar nature. The plans which had chiefly prevailed were, founding upon piling carried up to about the level of low water, constructing within 